\title{
ELISA com MSP5 recombinante truncada para detecção de anticorpos contra Anaplasma marginale em bovinos ${ }^{1}$
}

\author{
Elaine S.P. Melo², Flábio R. Araújo ${ }^{3 *}$, Carlos A.N. Ramos ${ }^{2}$, Cleber O. Soares ${ }^{3}$, Grácia \\ M.S. Rosinha ${ }^{3}$, Carina Elisei ${ }^{4}$ e Cláudio R. Madruga ${ }^{3}$
}

\begin{abstract}
Melo E.S.P., Araújo F.R., Ramos C.A.N., Soares C.O., Rosinha G.M.S., Elisei C. \& Madruga C.R. 2007. [ELISA based on recombinant truncated MSP5 for detection of antibodies against Anaplasma marginale in cattle.] ELISA com MSP5 recombinante truncada para deteç̧ão de anticorpos contra Anaplasma marginale em bovinos. Pesquisa Veterinária Brasileira 27(7):301-306. Embrapa Gado de Corte, Cx. Postal 154, Campo Grande, MS 79002-970, Brazil. E-mail: flabio@cnpgc.embrapa.br

The objective of this study was the production and solubilization of recombinant truncated MSP5 of Anaplasma marginale and the evaluation of its performance in an enzyme-linked immunosorbent assay (ELISA), to detect antibodies against the rickettsia in cattle. The fragment of msp5 gene, except the hydrophobic N-terminal region, was amplified by PCR, cloned in pTrcHis-TOPO plasmid and expressed in Escherichia coli. Solubilization of the recombinant protein was evaluated in different $\mathrm{pHs}$ and concentrations of urea. The sensibility and specificity of the assay were evaluated with 66 sera from cattle experimentally-infected and 96 sera from cattle free of $A$. marginale defined by polymerase chain reaction for msp5 gene. Serum samples from 1,666 cattle from Brazil - states of Rio Grande do Sul (73), Mato Grosso do Sul (91), Pernambuco (86), Bahia (314) and Minas Gerais (267), Uruguay (32) and Costa Rica (803), were tested by ELISAs with recombinant truncated MSP5 and with recombinant MSP1a, and the agreement between both ELISAs was calculated. ELISA with recombinant truncated MSP5 protein detected infected animals with sensibility of $96.97 \%$ and specificity of $100 \%$. In cattle experimentally-infected, the ELISA detected antibodies from the $12^{\text {th }}$ day post-infection (DPI) to the end of the experiment, at the $37^{\text {th }}$ DPI. The agreement between the ELISAs with truncated MSP5 and MSP1a antigens was 95.67\%, with a kappa index of 0.81. Disagreement results showed significative difference $(\mathrm{p}<0.001)$. Antibodies for $A$. marginale were detected in animals of the all the region analyzed. The ELISA with recombinant truncated MSP5 showed a good performance in ELISA for detention of antibodies against $A$. marginale, with high sensitivity and specificity, representing an important tool for the diagnosis of anaplasmose bovine in epidemiological studies.
\end{abstract}

INDEX TERMS: Anaplasma marginale, ELISA, MSP5, solubilization, recombinant protein.

RESUMO.- Os objetivos deste estudo foram produzir e solubilizar a proteína MSP5 recombinante truncada de Anaplasma marginale, e avaliar seu desempenho em um ensaio de imunoadsor-

\footnotetext{
${ }^{1}$ Recebido em 7 de março de 2007. Aceito para publicação em 3 de abril de 2007.

2 Programa de Pós-Graduação em Ciência Animal, Universidade Federal de Mato Grosso do Sul (UFMS), Cx. Postal 649, Campo Grande, MS 79070-900, Brasil.

3 Área de Sanidade Animal, Embrapa Gado de Corte, Rodovia BR 262 Km 4, Cx. Postal 154, Campo Grande, MS 79002-970. * Autor para correspondência: flabio@cnpgc.embrapa.br

${ }^{4}$ Bolsista DCR CNPq.
}

ção enzimática indireto (ELISA) para detecção de anticorpos contra a riquétsia. $\mathrm{O}$ gene $m s p 5$, exceto a região $\mathrm{N}$-terminal hidrofóbica, foi amplificado por PCR, clonado em plasmídeo pTrcHis-TOPO e expresso em Escherichia coli. A solubilização da proteína recombinante foi avaliada em diferentes pHs e concentrações de uréia. A sensibilidade e a especificidade do ensaio foram avaliados testando-se 66 soros de animais infectados experimentalmente $\operatorname{com} A$. marginale e 96 soros negativos, com o estado de infecção destes animais confirmado por PCR. Um total de 1.666 amostras de soros bovino, provenientes do Brasil - Rio Grande do Sul (73), Mato Grosso do Sul (91), Pernambuco (86), Bahia (314) e Minas Gerais (267)-, Uruguai (32) e Costa Rica 
(803) foram testadas nos ELISAs com MSP5 truncada e com MSP1a recombinantes e a concordância entre os dois testes foi avaliada. O ELISA indireto com MSP5 truncada foi capaz de detectar animais infectados com $96,97 \%$ de sensibilidade e $100 \%$ de especificidade. Nos animais infectados experimentalmente, o ELISA detectou anticorpos do $12^{\circ}$ até o último dia de observação (37을 dia). Os ELISAs para MSP5 e MSP1a apresentaram concordância de $95,67 \%$, com índice kappa de 0,81 . Os resultados discordantes apresentaram uma diferença significativa ( $p<0,001$ ). Anticorpos contra $A$. marginale foram detectados em animais de todas as regiões estudadas. O ELISA com MSP5 recombinante truncada apresentou bom desempenho na detecção de anticorpos contra $A$. marginale, com alta sensibilidade e especificidade, representando uma importante ferramenta para o diagnóstico da anaplasmose bovina em estudos epidemiológicos.

TERMOS DE INDEXAÇÃO: Anaplasma marginale, ELISA, MSP5, solubilização, proteína recombinante.

\section{INTRODUÇÃO}

Anaplasma marginale é uma bactéria intraeritrocítica obrigatória que causa anaplasmose em bovinos e outros ruminantes (Palmer 1999). É classificada na Ordem Rickettsiales, que foi recentemente reorganizada em duas Famílias Anaplasmataceae e Rickettsiaceae baseada na análise genética de $16 \mathrm{~S}$ rRNA, groELS e genes que codificam para proteínas de superfície (Dumler et al. 2001). A anaplasmose é uma doença economicamente importante em muitas regiões tropicais e subtropicais do mundo, por determinar perdas econômicas devido à mortalidade, redução do peso e da produção de leite e custos com tratamentos (Kocan et al. 2003).

Muitas técnicas sorológicas têm sido descritas para o diagnóstico de infecções por $A$. marginale, incluindo teste de aglutinação em cartão (Amerault \& Roby 1968), imunofluorescência, fixação de complemento (Gonzalez et al. 1978), radioimunoensaio (Schuntner \& Leatch 1988) e ensaio de imunoadsorção enzimática (ELISA) (Thoen et al. 1980). Dentre estes, o ELISA é o teste mais aplicado (Thoen et al. 1980, Winkler et al. 1987, Duzgun et al. 1988, Nielsen et al. 1996). No entanto, existem problemas de especificidade nestes ELISAs que utilizam como antígeno, corpúsculos iniciais parcialmente purificados de eritrócitos infectados, que podem reagir inespecificamente com anticorpos anti-eritrócitos presente no soro dos animais testados (Duzgun et al. 1988).

Com o advento da tecnologia do DNA recombinante, que possibilitou a produção de grandes quantidades de proteínas heterólogas em culturas bacterianas, as pesquisas voltadas para o desenvolvimento de testes sorológicos foram focadas nas proteínas de membrana dos corpúsculos iniciais de $A$. marginale (Torione de Echaide et al. 1998). Seis proteínas principais de superfície (major surface proteins-MSPs: MSP1a, MSP1b, MSP2 MSP3, MSP4 e MSP5) foram inicialmente identificadas em $A$. marginale derivado de eritrócitos bovinos e de tecidos de carrapatos (Barbet et al. 1987, Oberle et al. 1988, Bowie et al. 2002). Essas proteínas, expostas na superfície da riquétsia, são facilmente acessíveis ao sistema imunológico do hospedeiro, e desempenham importantes funções para a sobrevivência do parasito (Arulkanthan et al. 1999).

A proteína MSP5 tem mostrado maior potencial para ser utilizada como antígeno em diagnóstico sorológico, devido às suas características de conservação entre diferentes espécies e isolados de Anaplasma sp. (Visser et al. 1992, Ndung'u et al. 1995). No entanto, diferentes técnicas utilizadas para sua produção e purificação têm influenciado negativamente a exeqüibilidade dos ensaios. Como exemplos, no ELISA competitivo, ocorrem problemas de especificidade, provavelmente relacionados à reação de anticorpos anti-proteína de ligação à maltose, a qual está fusionada à MSP5 (Torione de Echaide et al. 1998). Já no ELISA indireto com MSP5, padronizado por Silva et al. (2006), a expressão de todo o gene, incluindo a região hidrofóbica $\mathrm{N}$-terminal, inviabilizou a purificação da proteína por cromatografia de afinidade em resina de agaroseníquel, dificultando a execução do teste.

Outro problema relacionado aos testes que empregam proteínas recombinantes produzidas em Escherichia coli consiste na eficiente solubilização das mesmas, já que, em muitos casos, são formados corpúsculos de inclusão altamente insolúveis na bactéria e os métodos de solubilização rotineiramente empregam agentes altamente desnaturantes, que alteram a conformação da proteína, e, conseqüentemente, sua antigenicidade (Patra et al. 2000).

Os objetivos deste estudo foram produzir a MSP5 recombinante truncada, excetuando o domínio hidrofóbico N-terminal da proteína, solubilizar a proteína e avaliar seu desempenho como antígeno em um ELISA indireto para o diagnóstico de $A$. marginale em bovinos.

\section{MATERIAL E MÉTODOS}

\section{Clonagem e expressão de MSP5 truncada}

A extração de DNA de Amaplasma marginale - Amaplasma foi realizada a partir de sangue infectado com isolado Pernambuco - Zona da Mata (PE-ZM), utilizando-se o kit Easy DNA (Invitrogen), conforme instruções do fabricante. A amplificação do fragmento gênico de msp5 foi realizada por PCR com os oligonucleotídeos iniciadores msp5 F: 5' CGCAGATCTAGCAAAATCGGCGAGAGGTTTACCACTTC 3' e msp5 R: 5' GCGCTGCAG-TGGCGCAAAATGCCCGACATACC 3', que amplificam todo o gene, exceto a região $\mathrm{N}$-terminal hidrofóbica, determinado pelo programa Protean (DNAStar). Dessa forma, foi amplificado um fragmento de $543 \mathrm{pb}$ (nucleotídeos 91 a 633). O produto da reação de amplificação foi utilizado para ligação ao plasmídeo $p$ TrcHis-TOPO (Invitrogen), conforme metodologia descrita pelo fabricante. $\mathrm{O}$ plasmídeo resultante $p \operatorname{Tr} C H i s-T O P O / m s p 5$ foi utilizado para transformar células de Escherichia coli TOP10 (Invitrogen), quimicamente competentes, que posteriormente foram semeadas em meio Luria-Bertani (LB) ágar com $100 \mu \mathrm{g} / \mathrm{mL}$ de ampicilina, as quais foram incubadas por 12 horas a $37^{\circ} \mathrm{C}$. Para verificar a presença e orientação dos insertos foi realizada PCR de colônia com os oligonucleotídeos iniciadores msp5 forward e pTrcHis reverse (vetor). A indução da expressão do gene msp5 foi realizada com $1 \mathrm{mM}$ de isopropil-tio-b-D-galactopiranosídeo (IPTG) por 6 horas a $37^{\circ} \mathrm{C}$ sob agitação (250xg).

\section{Solubilização da MSP5 truncada}

Após indução, $400 \mathrm{~mL}$ da cultura foram centrifugados a $12.000 \mathrm{xg}$ a $4^{\circ} \mathrm{C}$ por 10 minutos e o sedimento suspenso e homogeneizado 
em $20 \mathrm{~mL}$ de tampão (tris-HCL 50mM, EDTA $5 \mathrm{mM}$ (pH 8,5), $2 \%$ de triton X-100 e $0,16 \mathrm{mg} / \mathrm{mL}$ de lisozima) e incubado por uma hora em temperatura ambiente. A solução foi sonicada oito vezes, por 30 segundos (output 40) (Branson Sonifier 250) em gelo e centrifugada a $10.000 \mathrm{xg}$ por 20 minutos a $4^{\circ} \mathrm{C}$. $\mathrm{O}$ sedimento foi suspenso em trisbase $100 \mathrm{mM}$, em diferentes concentrações de uréia e pHs. O sedimento foi homogeneizado e centrifugado a $12.000 \times$ x por 10 minutos a $4^{\circ} \mathrm{C}$ para obtenção das frações solúvel e insolúvel. A fração solúvel foi diluída lentamente em $10 \mathrm{~mL}$ de tris-base $50 \mathrm{mM}$, uréia 2 M e o pH de toda a solução ajustado para 8,0.

\section{Purificação e avaliação da antigenicidade de MSP5 truncada}

A purificação da proteína foi realizada por cromatografia de afinidade em coluna de agarose-níquel (ProBond, Invitrogen), em condições nativas, adicionando-se às soluções $2 \mathrm{M}$ de uréia. $\mathrm{A}$ proteína foi concentrada em filtro Centricon YM-10 (Millipore) e sua concentração avaliada pelo método de BradFord (Protein Assay, BioRad) de acordo com instruções do fabricante. A antigenicidade de MSP5 truncada recombinante foi verificada por Western blot, com os anticorpos monoclonais ANAF16C1 anti-MSP5 (1:500) e anti 6xhistidina (1:3.000) (Amersham Pharmacia).

\section{Padronização e avaliação do ELISA com MSP5 truncada}

Para a padronização do ELISA com MSP5, diluições ótimas do antígeno, soros, conjugado e tampões utilizados no ensaio, assim como o tempo de parada da reação enzimática, foram avaliados com seis amostras de soros de bovinos negativos e seis positivos para $A$. marginale por PCR.

O ELISA foi realizado em microplacas (Costar 3590, Corning) sensibilizadas com 13ng/poço de MSP5 recombinante truncada, diluída em PBST e incubadas a $4^{\circ} \mathrm{C}$ por 12 horas. As placas foram bloqueadas com PBST contendo 5\% de soro eqüino livre de imunoglobulinas $\left(100 \mu \mathrm{L} /\right.$ poço) por uma hora a $37^{\circ} \mathrm{C}$. Após cinco lavagens com PBST, os soros testes, controles positivos e negativos, diluídos 1:600 em PBST (100 $\mu \mathrm{L} /$ poço), foram adicionados e as placas incubadas por uma hora a $37^{\circ} \mathrm{C}$. Após mais cinco lavagens, foi adicionado o conjugado anti-lgG bovina/peroxidase (Sigma), diluído 1:10.000 em PBST (100 $\mu \mathrm{L} /$ poço), seguido de incubação por 30 minutos a $37^{\circ} \mathrm{C}$. Após cinco lavagens o cromógeno/substrato ortofenilenodiamina (OPD; Sigma) $/ \mathrm{H}_{2} \mathrm{O}_{2}(50 \mu \mathrm{L} /$ poço) foi adicionado. A reação enzimática foi parada após cinco minutos pela adição $\mathrm{H}_{2} \mathrm{SO}_{4} 2,5 \mathrm{~N}$ $(100 \mu \mathrm{L} /$ poço) e os resultados obtidos em espectrofotômetro para microplacas (EL-800, Bio-Tek), com comprimento de onda de $490 \mathrm{~nm}$.

O cálculo da linha de corte (cutoff) foi determinado para cada placa de acordo com Frey et al. (1998), utilizando 12 controles negativos e estabelecendo o nível de confiança de $99,0 \%$.

A determinação da sensibilidade, especificidade, valor preditivo positivo, valor preditivo negativo e precisão do ELISA com MSP5 foi realizada de acordo com Coggon et al. (1993). Para a avaliação destes parâmetros foram testadas 162 amostras de soros, sendo 96 soros negativos e 66 soros de animais infectados experimentalmente com isolado PE-ZM de A. marginale obtidos do banco de soros da Área de Sanidade Animal da Embrapa Gado de Corte. O estado de infecção destes animais foi confirmado por PCR para o gene msp5. Destes animais infectados experimentalmente, seis foram acompanhados a partir de uma semana antes da inoculação até 37 dias após inoculação.

Um total de 1.666 amostras de soros foi testado no ELISA com MSP5 e no ELISA com MSP1a recombinante descrito por Araújo et al. (2005), para avaliar a concordância entre os testes. Os soros testados foram provenientes de regiões distintas do Brasil: Rio Grande do Sul (73), Mato Grosso do Sul (91), Pernambuco (86), Bahia (314) e
Minas Gerais (267), além do Uruguai (32) e da Costa Rica (803). Esses soros estavam estocados a $-20^{\circ} \mathrm{C}$, no banco de soros da Embrapa Gado de Corte, e foram escolhidos baseado na disponibilidade dos mesmos.

\section{Análise estatística}

A avaliação da concordância entre os ELISAs com MSP5 e MSP1a foi determinada pelo índice kappa de acordo com Kramer e Feinstein (1981). Para avaliar a significância dos resultados discordantes entre os ELISAs foi aplicado o teste de qui-quadrado com nível de significância de $5 \%$.

\section{RESULTADOS E DISCUSSÃO}

A amplificação do fragmento gênico que codifica para a porção hidrofílica de $m s p 5$, como esperado, resultou em um produto de cerca de 543 pb (Fig.1). Os amplicons clonados em pTrcHis-TOPO, geraram os plasmídeos recombinantes pTrcHisTOPO/MSP5, confirmados por PCR de colônia. A expressão do fragmento do gene msp5 atingiu produção máxima após 6 horas de indução com IPTG e resultou em uma proteína truncada de aproximadamente $16 \mathrm{kDa}$, que corresponde à massa molecular esperada da porção hidrofílica de MSP5 ( 13 kDa) e a do peptídeo $\mathrm{N}$-terminal codificado pelo vetor $p$ TrcHis-TOPO (3 kDa), que corresponde a cauda de seis histidinas (Fig.2).

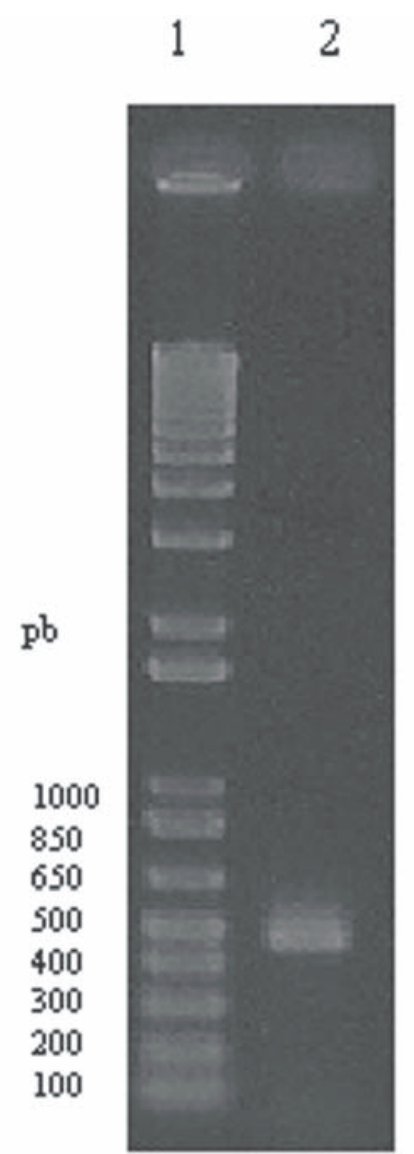

Fig.1. Amplificação do gene msp5 de isolado brasileiro (Pernambuco - Zona da Mata) de Anaplasma marginale por PCR. Linha 1: Marcador de pares de base $1 \mathrm{~Kb}$ Plus (Invitrogen). Linha 2: Fragmento do gene msp5 amplificado. 


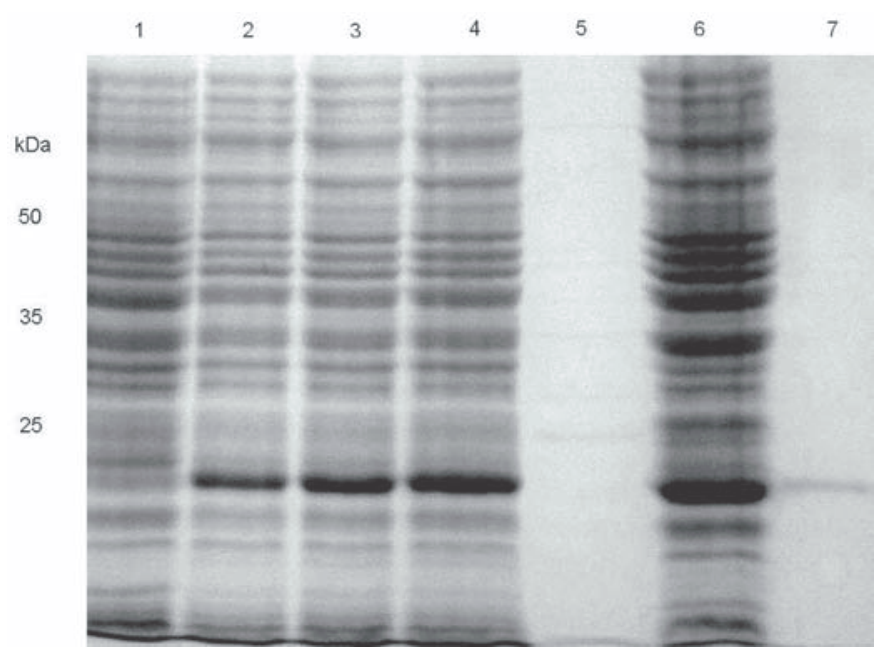

Fig.2: Expressão de msp5 de isolado brasileiro (Pernambuco - Zona da Mata) de Anaplasma marginale. Linha 1: Escherichia coli TOP10 transformada com pTrcHis-TOPO/msp5 sem indução com IPTG. Linha 2: indução por $2 \mathrm{~h}$ com IPTG. Linha 3: indução por $4 \mathrm{~h}$ com IPTG. Linha 4: indução por $6 \mathrm{~h}$ com IPTG. Linha 5: fração insolúvel. Linha 6: fração solúvel. Linha 7: MSP5 recombinante purificada (16kDa).

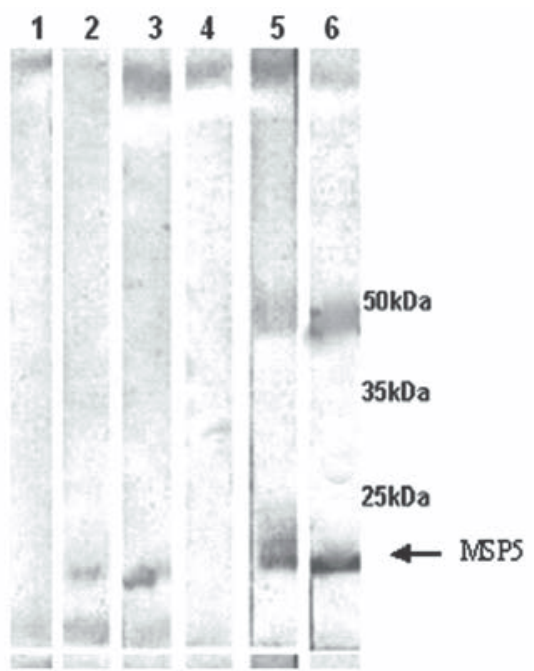

Fig.3. Western Blot com anticorpo monoclonal anti-MSP5 ANAF16C1 (Linhas 1-3) e com anti-histidina (Linhas 4-6). Linhas 1 e 4 : Escherichia coli TOP10 transformada com pTrcHis-TOPO/msp5 sem indução com IPTG. Linhas 2 e 5: E. coli TOP10 transformada com pTrcHis-TOPO/msp5 após 6h de indução com IPTG. Linhas 3 e 6: MSP5 recombinante truncada purificada $(16 \mathrm{kDa})$.

A proteína, presente em corpúsculos de inclusão insolúveis, foi solubilizada eficientemente quando empregou-se $2 \mathrm{M}$ de uréia, em pH 12,5. A solubilização possibilitou a purificação por cromatografia de afinidade e a obtenção de uma proteína pura. Silva et al. (2006), em estudo semelhante, empregando o mesmo sistema de expressão, não obteve o mesmo êxito na purificação por cromatografia de afinidade ao utilizar proteína MSP5 integral, o que só foi possível por eletroeluição, que é um método de baixo rendimento, e portanto pouco vantajoso para produção de proteína em larga escala.
Desta forma, a maior capacidade de solubilização e purificação pode ser atribuída à utilização da proteína MSP5 truncada e fusionada à seqüência $\mathrm{N}$-terminal de seis histidinas.

Trabalhos anteriores demonstraram que MSP5 é uma proteína codificada por uma única cópia de gene, altamente conservada entre diferentes isolados de $A$. marginale, bem como Anaplasma centrale, A. ovis e A. phagocytophilum, no que diz respeito ao epítopo definido pelo anticorpo monoclonal ANAF16C1 (Visser et al. 1992, Molad et al. 2004, Dreher et al. 2005). Conforme confirmado neste estudo, em que a proteína MSP5 truncada foi reconhecida especificamente por este anticorpo e pelo anticorpo monoclonal anti-histidina (Fig.3), mesmo após tratamento com uréia. Visser et al. (1992) e Munodzana et al. (1998) relatam uma perda parcial da capacidade de ligação do anticorpo monoclonal ANAF16C1 quando há alterações na estrutura secundária da MSP5, caracterizando o epitopo reconhecido como conformacional. A proteína manteve sua atividade antigênica após o procedimento de solubilização, evidenciando que não houve alterações apreciáveis de sua conformação, o que foi fundamental para a realização do ensaio sorológico.

Os resultados do ELISA com MSP5 truncada estão demonstrados no Quadro 1 e serviram como base para o cálculo dos parâmetros (sensibilidade, especificidade, valor preditivo

Quadro 1. Resultados do ELISA com MSP5 recombinante truncada com soros de bovinos livres de infecção e infectados experimentalmente por Anaplasma marginale

\begin{tabular}{cccc}
\hline \multirow{2}{*}{ ELISA MSP5 } & \multicolumn{3}{c}{ Estado de infecção dos bovinos (PCR) } \\
\cline { 2 - 4 } & Positivo & Negativo & Total \\
\hline Positivo & 64 & 0 & 64 \\
Negativo & 2 & 96 & 98 \\
Total & 66 & 96 & 162
\end{tabular}

positivo, valor preditivo negativo e precisão) para avaliar o desempenho do ensaio (Quadro 2). O ELISA indireto com MSP5 recombinante truncada foi capaz de detectar bovinos experimentalmente infectados com $A$. marginale com uma sensibilidade de $96,97 \%$. A sensibilidade deste ELISA foi superior ao encontrado nos ELISAs indiretos com antígeno bruto de Nielsen et al. (1996) (87,3\%), Montenegro-James et al. (1990) (93\%) e no ELISA competitivo desenvolvido por Torione de Echaide et al. (1998) (96\%). No entanto, foi inferior ao ELISA indireto com antígeno bruto reportado por Madruga et al. (2000) (100\%). Duas explicações para este resultado podem ser: i) maior diversidade de epítopos presente no antígeno com corpúsculo inicial e ii) o teste padrão utilizado por Ma-

\begin{tabular}{lc}
$\begin{array}{c}\text { Quadro 2. Desempenho do ELISA com MSP5 } \\
\text { recombinante truncada na deteção de } \\
\text { anticorpos contra Anaplasma }\end{array}$ & marginale \\
\hline Parâmetros & $\%$ \\
\hline Sensibilidade & 96,97 \\
Especificidade & 100,00 \\
Valor Preditivo Positivo & 100,00 \\
Valor Preditivo Negativo & 97,96 \\
Precisão & 98,76
\end{tabular}


druga et al. (2000) para determinar o estado de infecção dos animais que foi a imunofluorescência indireta, com sensibilidade e especificidade inferior à PCR. Baseado nestas observações, verifica-se que um teste de diagnóstico em desenvolvimento, deve sempre ser comparado a outro de maior sensibilidade e especificidade.

A especificidade do ELISA com MSP5 foi superior ao ELISA competitivo de Torione de Echaide et al. (1998) (95\%). Resultado este que pode ser devido à utilização de proteína de ligação à maltose (maltose binding protein - MBP) fusionada à MSP5 como antígeno no ELISA competitivo. A MBP pode induzir reações falso-positivas decorrentes de interações inespecíficas entre anticorpos anti-MBP e MBP-MSP5, bloqueando a ligação do anticorpo monoclonal ANAF16C1, mesmo depois de realizar uma pré-adsorção do soro à MBP (Torione de Echaide et al. 1998). A especificidade deste ELISA também foi superior aos ELISAs com corpúsculo inicial desenvolvido por Montenegro-James et al. (1990) (96\%), Nielsen et al. (1996) $(99,6 \%)$ e Madruga et al. (2000) (96\%). Nesses ensaios, provavelmente ocorreram contaminação dos antígenos com proteínas de eritrócitos, as quais podem reagir inespecificamente com anticorpos presentes no soro, resultando assim em reações falso positivas, que interferem diretamente na especificidade do teste (Barry et al. 1986).

Com relação ao acompanhamento dos animais experimentalmente infectados, o ELISA com MSP5 truncada recombinante detectou anticorpos específicos a partir do $12^{\circ}$ dia após inoculação até o 37º quando foi realizada a última análise (Fig.4), enquanto que a PCR começou a detectar riquetsemia a partir do $9^{\circ}$ dia, uma diferença pouco importante, ao considerar que a PCR é sabidamente uma técnica alta sensibilidade (Corona et al. 2000).

Os ELISAs com MSP5 e MSP1a detectaram 166 animais infectados e 1.428 não infectados, o que correspondeu a alta concordância de 95,67\% definido pelo índice k de 0,81 (Quadro 3) (Ansari-Lari 2005). Os ELISAs foram capazes de detectar bovinos infectados em todas as regiões brasileiras estudadas (Rio Grande do Sul, Mato Grosso do Sul, Pernambuco, Bahia e Minas Gerais), assim como do Uruguai e da Costa Rica. A concordância entre os ELISAS e o reconhecimento destas proteínas pelo soro de bovinos de diferentes regiões deveuse provavelmente ao uso de proteínas com epítopos conser-

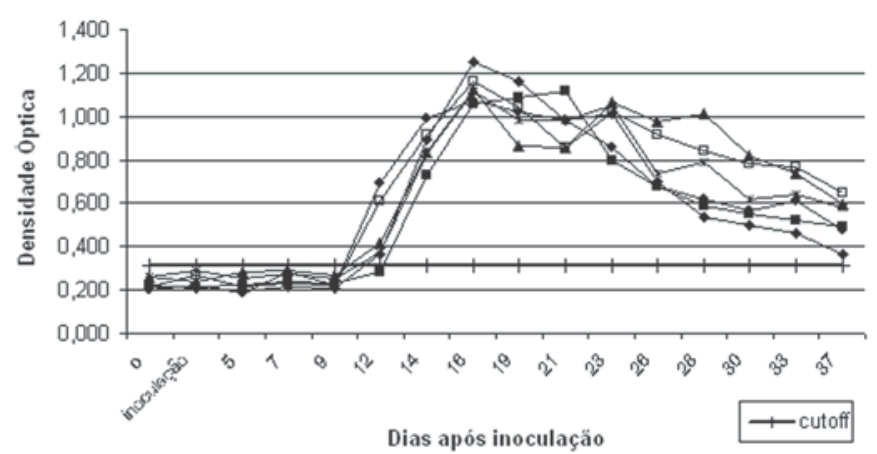

Fig.4. Avaliação da resposta de anticorpos contra MSP5 recombinante truncada desenvolvida por seis bovinos infectados experimentalmente com Anaplasma marginale.
Quadro 3. Concordância entre os resultados dos ELISAs com MSP5 e MSP1a recombinantes na deteç̧ão de anticorpos contra Anaplasma marginale utilizando soros provenientes de regiões distintas do Brasil (Rio Grande do Sul, Mato Grosso do Sul, Pernambuco, Bahia, Minas Gerais), Uruguai e Costa Rica

\begin{tabular}{cccccc}
\hline ELISA & & \multicolumn{3}{c}{ MSP1a } & Índice k \\
\cline { 3 - 5 } MSP5 & & Positivo & Negativo & Total & \\
\hline Positivo & 166 & 29 & 195 & 0,81 \\
Negativo & 43 & 1428 & 1471 & \\
Total & 209 & 1457 & 1666 &
\end{tabular}

vados, pois as proteínas MSP1a e MSP5 utilizadas neste estudo são baseadas no fragmento do gene msp1a e msp5 respectivamente, que codificam para o domínio hidrofílico da região C-terminal de MSP1a e N-terminal de MSP5, que são conservados. Este resultado também ressalta o bom desempenho do ELISA com MSP5, uma vez que apresentou alta concordância com um ensaio de $99 \%$ de sensibilidade e $100 \%$ de especificidade (Araújo et al. 2005).

Em relação aos resultados discordantes entre os ELISAs com MSP1a e MSP5 recombinantes, encontrou-se um número significativamente maior $(\mathrm{p}<0,001)$ de soros negativos no ELISA com MSP5 truncada e positivos no ELISA com MSP1a, evidenciando que, como soros de animais naturalmente infectados, ocorre uma maior sensibilidade nesse último teste. No entanto, é provável que essa diferença de sensibilidade não reflita em alterações na interpretação da situação epidemiológica.

O ELISA com MSP5 recombinante truncada apresentou bom desempenho na deteç̧ão de anticorpos contra $A$. marginale, com alta sensibilidade e especificidade, representando uma importante ferramenta para o diagnóstico da anaplasmose bovina em estudos epidemiológicos.

Agradecimentos.- Este trabalho recebeu suporte da Fundação de Apoio ao Desenvolvimento do Ensino, Ciência e Tecnologia do Estado de Mato Grosso do Sul (FUNDECT), Conselho Nacional de Desenvolvimento Científico e Tecnológico (CNPq) e Financiadora de Estudos e Projetos (FINEP).

\section{REFERÊNCIAS}

Alleman A.R. \& Barbet A.F. 1996. Evaluation of Anaplasma marginale major surface protein 3 (MSP3) as a diagnostic test antigen. J. Clin. Microbiol. 34:270-276.

Amerault T.E. \& Roby T.O. 1968. A rapid card agglutination test for bovine anaplasmosis. J. Am. Vet. Med. Assoc. 153:1828-1834.

Ansari-Lari M. 2005. Comparison between two tests results, k statistic instead of simple overall agreement. Vet. Parasitol. 133:369-370.

Araújo F.R., Melo V.S.P., Ramos C.A.N., Madruga C.R., Soares C.O., Kessler R.H., Almeida N.F., Araújo G.S., Torres Jr R.A.A., Fragoso S.P., Arauco P.R.C., Bacanelli G., Oliveira M.B. \& Santos L.R. 2005. Development of enzymelinked immunoadsorbent assays based on recombinant MSP1a and MSP2 of Anaplasma marginale. Mem. Inst. Oswaldo Cruz 100:765-769.

Arulkanthan A., Brown W.C., McGuire T.C. \& Knowles D.P. 1999. Biased immunoglobulin G1 isotype responses induced in cattle with DNA expressing msp1a of Anaplasma marginale. Infect. Immun. 67:3481-3287.

Barry D.N., Parker R.J., De Vos A.J., Dunster P. \& Rodwell B.J. 1986. A microplate enzyme-linked immunosorbent assay for measuring antibody to Anaplasma marginale in cattle serum. Aust. Vet. J. 63:76-79.

Barbet A.F., Palmer G.H., Myler P.J. \& McGuire T.C. 1987. Characterization of 
an immunoprotective protein complex of Anaplasma marginale by cloning and expression of the gene coding for polypeptide Am105L. Infect. Immun. 55:2428-2435

Bowie M.V., Fuente J., Kocan K.M., Blouin E.F. \& Barbet A.F. 2002. Conservation of major surface protein 1 genes of Anaplasma marginale during cyclic transmission between ticks and cattle. Gene. 282:95-102.

Coggon T., Rose G. \& Barker D.J. 1993. Measurement, error and bias, p.2025. In: Coggon T., Rose G. \& Barker D.J. (ed.), Epidemiology for the Uninitiated. Vol.3. BJM Publishing Group, London.

Corona B., Mazorra L.M., Blandino T. \& Martínez S. 2000. Detección de Anaplasma marginale mediante amplificación del gen msp5. Rev. Sal. Animal. 22:168-173.

Dreher U.M., Fuente J., Hofmann-Lehmann R., Meli M.L., Pusterla N., Kocan K.M., Woldehiwet Z., Braun U. \& Regula G. 2005. Serologic cross-reactivity between Anaplasma marginale and Anaplasma phagocytophilum. Clin. Diagn. Lab. Immunol. 12:1177-1183.

Dumler J.S., Barbet A.F., Bekker C.P., Dasch G.A., Palmer G.H., Ray S.C., Rikihisa Y. \& Rurangirwa F.R. 2001. Reorganization of genera in the families Rickettsiaceae and Anaplasmataceae in the order Rickettsiales: unification of some species of Ehrlichia with Anaplasma, Cowdria with Ehrlichia and Ehrlichia with Neorickettsia, descriptions of six new species combinations and designation of Ehrlichia equi and 'HGE agent' as subjective synonyms of Ehrlichia phagocytophilum. Int. J. Syst. Evol. Microbiol. 51:2145-2165.

Duzgun A., Schuntner C.A., Wright I.G., Leatch G. \& Waltisbuhl D.J. 1988. A sensitive ELISA technique for the diagnosis of Anaplasma marginale infections. Vet. Parasitol. 29:1-7.

Frey A., Canzio J. \& Zurakowski D. 1998. A statistically defined endpoint titer determination method for immunoassays. J. Immunol. Meth. 221:35-41.

Fuente J., Garcia-Garcia J.C., Blouin E.F. \& Kocan K.M. 2001. Differential adhesion of major surface proteins $1 \mathrm{a}$ and $1 \mathrm{~b}$ of the ehrlichial cattle pathogen Anaplasma marginale to bovine erythrocytes and tick cells. Int. J. Parasitol. 31:145-153.

Gonzales E.F., Long R.F. \& Todorovic R.A. 1978. Comparisons of the complement-fixation, indirect fluorescent antibody, and card agglutination tests for the diagnosis of bovine anaplasmosis. Am. J. Vet. Res. 39:15381541.

Knowles D.P., Torioni de Echaide S., Palmer G., McGuire T., Stiller D. \& McElwain T. 1996. Antibody against an Anaplasma marginale MSP5 epitope common to tick and erythrocyte stages identifies persistently infected cattle. J. Clin. Microbiol. 34:2225-2230.

Kocan K.M., Fuente J., Guglielmone A.A. \& Melendez R.D. 2003. Antigens and alternatives for control of Anaplasma marginale infection in cattle. Clin. Microbiol. Rev. 16:698-712.

Kramer M.S. \& Feinstein A.R. 1981. Clinical biostatistics. LIV. The biostatistics of concordance. Clin. Pharmacol. Ther. 29:111-123.

Madruga C.R., Marques A.P., Leal C.R.B., Carvalho C.M.E., Araújo F.R. \& Kessler R.H. 2000. Evaluation of an enzyme-linked immunosorbent assay to detect antibodies against Anaplasma marginale. Pesq. Vet. Bras. 20:109-112.

McGarey D.J., Barbet A.F., Palmer G.H., McGuire T.C. \& Allred D.R. 1994. Putative adhesins of Anaplasma marginale: major surface polypeptides 1a and 1b. Infect. Immun. 62:4594-4601.

Molad T., Brayton K.A., Palmer G.H., Michaeli S. \& Shkap V. 2004. Molecular conservation of MSP4 and MSP5 in Anaplasma marginale and A. centrale vacine strain. Vet. Microbiol. 100:55-64.

Montenegro-James S., Guillen A.T., Ma S.J., Tapang P., Abdel-Gawad A., Toro M. \& Ristic M. 1990. Use of the dot enzyme-linked immunosorbent assay with isolated Anaplasma marginale initial bodies for serodiagnosis of anaplasmosis in cattle. J. Am. Vet. Med. Assoc. 51:1518-1521.

Munodzana D., McElwain T.F., Knowles D. \& Palmer G.H. 1998. Conformational dependence of Anaplasma marginale major surface protein 5 surfaceexposed B-cell epitopes. Infect. Immun. 66:2619-2624.

Ndung'u L.W., Aguirre C., Rurangirwa F.R., McElwain T.F., McGuire T.C., Knowles D. \& Palmer G.H. 1995. Detection of Anaplasma ovis infection in goats by major surface protein 5 competitive inhibition enzyme-linked immunosorbent assay. J. Clin. Microbiol. 33:675-679.

Nielsen K., Smith P., Gall D., Torione de Echaide S., Wagner G. \& Dajer A. 1996. Development and validation of an indirect enzyme immunoassay for detection of antibody to Anaplasma marginale in bovine sera. Vet. Parasitol. 67:133-142.

Oberle S.M., Palmer G.H., Barbet A.F. \& McGuire T.C. 1988. Molecular size variations in an immunoprotective protein complex among isolates of Anaplasma marginale. Infect. Immun. 56:1567-1573.

Palmer G.H., Rurangirwa F.R., Kocan K.M. \& Brow W.C. 1999. Molecular basis for vaccine development against the ehrlichial pathogen Anaplasma marginale. Today 15:253-300.

Patra A.K., Mukhopadhyay R., Mukhija R., Krishnan A., Garg, L.C. \& Panda A. K. 2000. Optimization of inclusion body solubilization and renaturation of recombinant human growth hormone from Escherichia coli. Prot. Expres. Purif. 18:182-192.

Schuntner C.A. \& Leatch G. 1988. Radioimmunoassay for Anaplasma marginale antibodies in cattle. Am. J. Vet. Res. 49:504-507.

Silva V.M.G., Araújo F.R., Madruga C.R.M., Soares C.O., Kessler R.H., Almeida M.A.O., Fragoso S.P., Santos L.R., Ramos C.A.N., Bacanelli G. \& Torres Júnior R.A.A. 2006. Comparison between indirect enzyme-linked immunosorbent assays for Anaplasma marginale antibodies with recombinant major surface protein 5 and initial body antigens. Mem. Inst. Oswaldo Cruz 5:511-516.

Thoen C.O., Blackburn B., Mills K., Lomme J. \& Hopkins M.P. 1980. Enzymelinked immunosorbent assay for detecting antibodies in cattle in a herd in which anaplasmosis was diagnosed. J. Clin. Microbiol. 11:499-502.

Torioni de Echaide S., Knowles D., McGuire T.C., Palmer G.H., Suarez C.E. \& McElwain T.F. 1998. Detection of cattle naturally infected with Anaplasma marginale in a region of endemicity by nested PCR and a competitive enzyme-linked immunosorbent assay using recombinant major surface protein 5. J. Clin. Microbiol. 36:777-782.

Trueblood E.S., McGuire T.C. \& Palmer G.H. 1991. Detection of Anaplasma marginale rickettsemia prior to onset of clinical signs by using an antigen capture enzime linked immunosorbent assay. J. Clin. Microbiol. 29:1542-1544.

Visser E.S., McGuire T.C., Palmer G.H., Davis W.C., Shkap V., Pipano E. \& Knowles D. 1992. The Anaplasma marginale msp5 gene encodes a 19kilodalton protein conserved in all recognized Anaplasma species. Infect and Immun. 60:5139-5144.

Winkler G.C., Brown G.M. \& Lutz H. 1987. Detection of antibodies on Anaplasma marginale by an improved enzyme-linked immnosorbent assay with sodium dodecyl sulfate-disrupted antigen. J. Clin. Microbiol. 25:633-636. 